\title{
Expression of NALPs in adipose and the fibrotic progression of non-alcoholic fatty liver disease in obese subjects
}

\author{
Rohini Mehta ${ }^{1,2}$, Arpan Neupane ${ }^{1,2}$, Lei Wang ${ }^{1,2}$, Zachary Goodman ${ }^{1,3}$, Ancha Baranova ${ }^{1,2}$ and Zobair M Younossi ${ }^{1,3^{*}}$
}

\begin{abstract}
Background: Visceral obesity is often accompanied by non-alcoholic fatty liver disease (NAFLD). Activation of NACHT, LRR and PYD domains-containing proteins (NALPs) may contribute to the release of pro-inflammatory cytokines by adipose and the obesity-associated progression of NAFLD to non-alcoholic steatohepatitis (NASH).

Methods: We analyzed visceral adipose expression of various NALPs and its downstream effectors caspase-1, ASC (Apoptosis-associated speck-like protein containing a CARD), IL-18 (Interleukin-18) and IL-1ß (Interleukin-1Beta) in obese subjects $(\mathrm{BMI} \geq 35)$ with biopsy proven NAFLD.

Results: In adipose samples collected from NASH and pericellular fibrosis patients cohorts, expression levels of NALPs and IL-1 $\beta$ were lower than that in non-NASH patients. In portal fibrosis, the levels of mRNA encoding anti-inflammatory NALP6 were upregulated. The expression levels of all NALPs were significantly co-correlated. Circulating IL-18 levels were associated with increased liver injury markers AST and ALT and portal fibrosis.

Conclusion: Our observations point at a possible shift in inflammation and fibrotic response from adipose tissue to liver and a possible negative feedback regulation of tissue inflammation that may instigate NAFLD severity.
\end{abstract}

Keywords: Obesity, NAFLD, Inflammasomes, Cytokines, Fibrosis

\section{Background}

The prevalence of obesity in United States has remained unabated over the past 10 years with $\sim 35 \%$ prevalence among adults [1]. A pro-inflammatory state (also referred to as low-grade chronic inflammation/meta-inflammation/ sterile inflammation) associated with visceral obesity, has been also shown to be strongly correlated with the development of non-alcoholic fatty liver disease (NAFLD) [2]. This non-pathogen associated pro-inflammatory state can be stimulated and propagated by a variety of damageassociated molecular patterns (DAMPs) that originate from damaged tissue and/or tissue under stress [3-5]. Once released, DAMPs bind to pattern-recognition receptors (PRRs) to elicit an immune response by promoting

\footnotetext{
* Correspondence: zobair.younossi@inova.org

'Betty and Guy Beatty Obesity and Liver Program, Inova Health System, Falls Church, VA, USA

${ }^{3}$ Center for Liver Diseases and Department of Medicine, Inova Fairfax Hospital, Falls Church, VA, USA

Full list of author information is available at the end of the article
}

the release of pro-inflammatory mediators and by recruiting the immune cells to the tissue.

Among the five main classes of vertebrate PRRs, the largest receptor family is comprised by nucleotide oligomerization and binding domain (NOD)-like receptors (NLRs) with a conserved NOD motif [6]. NLRs are believed to be the most evolutionarily ancient family of PRRs [7]. NACHT, LRR and PYD domains-containing proteins (NLRPs/NALPs) belong to the NOD-like receptor (NLR) family that differs from other NLRs by their N-terminal PYD domains $[8,9]$.

Recently NALPs have attracted attention as PRRs that link recognition of DAMPs with the regulation of inflammatory response $[7,10]$. Human genome encodes 14 NALPs, some of which are required for inflammasome formation [9]. The inflammasomes are large, signal-induced multiprotein complexes responsible for the proteolytic cleavage and activation of procaspases-1. In turn, activated caspase-1 promotes maturation of the pro-inflammatory

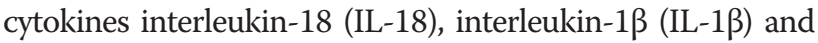


interleukin-33 (IL-33) $[10,11,12]$. The NALP1 inflammasome is composed of NALP1, apoptosis-associated specklike protein containing a carboxy-terminal CARD (ASC), caspase-1, and caspase-5, whereas the NALP2/3 inflammasome contains NALP2 or NALP3, CARDINAL, ASC, and caspase-1 [13].

The downstream targets of inflammasomes include known regulators of inflammation and immunity- IL-1 $\beta$ and IL-18. IL-1 $\beta$ triggers the production of interleukin- 6 (IL-6) and tumor necrosis factor-alpha (TNF- $\alpha$ ), two cytokines that elicits immune cell migration and infiltration into tissue [14], and promote the generation and maintenance of interferon-gamma (IFN- $\gamma$ ) and interleukin17 (IL-17) producing T cells [15]. Interleukin-18 (IL-18) incites immune cell recruitment and activation [11] and influences natural killer (NK) cell and $\mathrm{T}$ cell effector responses $[16,17]$.

A large number of recent studies have shown adipose tissue to be the major source of inflammatory molecules in obesity [18-21]. The expression patterns of NALPs have not been previously explored in visceral adipose. It is reasonable to speculate that NALPs may be activated in adipose tissue of obese individuals and that these NALPs may contribute to the release of pro-inflammatory IL-1 $\beta$ and IL-18 from adipocytes, the development of the systemic inflammation and the obesity-associated progression of non-alcoholic fatty liver disease (NAFLD) to nonalcoholic steatohepatitis (NASH).

With this in mind, we profiled visceral adipose expression of 14 NALPs as well as caspase-1, ASC, IL-18 and IL- $1 \beta$ in 45 obese subjects (BMI $\geq 35$ ) with biopsy proven NAFLD. Expression levels of NALPs were correlated to the serum indicators of system-wide inflammation IL- $1 \beta$ and IL-18 and to various parameters describing the underlying liver pathology.

\section{Methods \\ Sample collection}

This study has been approved by Internal Review Board of Inova Fairfax Hospital. After written informed consent, omental adipose tissue and serum samples from 45 obese patients (BMI = 4711$)$ undergoing bariatric surgery were collected. The samples were immediately flash frozen in liquid nitrogen and added to the repository of specimens stored at $80 \mathrm{C}$. The samples were de-identified in compliance with HIPAA regulations. For each patient, a liver biopsy was also performed and subjected to histopathological evaluation. Clinical data were available for all the samples in the repository and included pre-surgery fasting glucose, serum aminotransferases (alanine aminotransferase (ALT) and aspartate aminotransferase (AST)) and lipid panel. None of the included subjects reported to have excessively consumed alcohol ( $>10$ grams/day in women and $>20$ grams/day in men) in the past 5 years. Other chronic liver diseases were excluded by negative serology for hepatitis B and C, no history of toxic exposure and no other cause of chronic liver disease.

\section{Pathological assessment}

After staining with hematoxylin-eosin or Masson trichrome, the slides were reviewed by single hepatopathologist (Z.G.) that followed a predetermined histologic grading system [22] that included quantitative evaluation of the fibrosis and various inflammatory features.

\section{Definitions and scoring}

Steatosis was histologically defined as the presence of $>5 \%$ hepatic fat with or without lobular inflammation and with/without portal inflammation and graded on a scale of 03 as follows: $0=$ none, $1 \leq 5 \%, 2=6-33 \%, 3=34-66 \%$, $4=>66 \%$. Immune cell infiltrates (lymphoplasmacytic cells, Kupffer cell hypertrophy and neutrophil presence) were scored on a score of 03 as follows: $0=$ none, $1=$ mild or few, 2 = moderate, $3=$ marked or many. Lobular inflammation was defined by sum of scores of the presence of lymphoplasmacytic cells, Kupffer cell hypertrophy and neutrophil infiltration. Portal inflammation, hepatocellular ballooning, pericellular/perisinusoidal fibrosis, and portal fibrosis were graded on a scale of 0 to 3: (0) none, (1) mild or few, (2) moderate, or (3) marked or many. Advanced fibrosis was defined by a sum of score of portal and pericellular fibrosis as being greater or equal to 3. Bridging fibrosis was scored as (0) none, (1) few bridges, or (2) many bridges. Cirrhosis was scored as (0) absent, (1) incomplete, or (2) established. NASH was histologically defined as steatosis, lobular inflammation, and ballooning degeneration with or without Mallory Denk bodies, and with or without pericellular fibrosis. Patients who had hepatic steatosis (with or without lobular inflammation) or NASH were considered to have NAFLD [22].

\section{RNA extraction and reverse transcription}

Total RNA was extracted from visceral adipose tissue (100 mg) using Aurum Total RNA Fatty and Fibrous Tissue Kit (Bio-Rad, USA) and eluted in $30 \mathrm{uL}$ of RNase free water (Fisher Scientific, USA). The quantity and purity of the extracted RNA was determined by absorbance at $260 \mathrm{~nm}$ (A260) and $280 \mathrm{~nm}$ (A280) measured by the GeneQuant1300 spectrophotometer (GE Healthcare, USA). A260/A280 ratio between 1.8 and 2.1 was considered as an indicator of high quality RNA. The integrity of total RNA was verified by $1 \%$ agarose gel electrophoresis with ethidium bromide $(10 \mu \mathrm{g} / \mathrm{ml})$. The results were documented using Molecular Imager (Bio-Rad, USA). All total RNA samples demonstrated a 2:1 intensity ratio of sharp, clear $28 \mathrm{~S}$ and $18 \mathrm{~S}$ rRNA bands.

To prevent deterioration of RNA during storage, cDNA synthesis was carried out on the same day as total 
RNA extraction using $\mathrm{RT}^{2}$ HT First Strand Kit (Qiagen). According to manufacturer s protocol, 1 ug of total RNA was subjected to a genomic DNA elimination step prior to reverse transcription. Reverse transcription was carried out in the presence of random hexamers and oligo$\mathrm{dT}$ and resultant cDNA preps were diluted to a final volume of $111 \mathrm{uL}$.

\section{Quantitative RT-PCR}

Validated primers for specific amplification of NALP1NALP14, Caspase-1, ASC, IL-1B and IL-18 mRNA were as described in relevant publications (see Additional file 1: Table S1). The specificity of each primer was verified using NCBI BLAST [23] and the correct size of PCR product was confirmed by gel electrophoresis in $2 \%$ agarose. For the purpose of normalization, visceral adipose validated housekeeping gene ACTB was used as the reference [24].

Quantitative real-time PCR was performed in a 96 well format in the Bio-Rad CFX96 Real Time System (BioRad, USA). The real-time PCR mixture consisted of $1 \mu \mathrm{L}$ cDNA corresponding to 1 ug of total RNA, $250 \mathrm{nM}$ primers and 1 Sso Fast Evagreen Supermix (BioRad, USA) in a final volume of $10 \mu \mathrm{L}$. Each plate included no template control to detect reagent contamination. Each run also included wells with TATA box binding protein (TBP) primer pair (Invitrogen, USA) and universal cDNA (Qiagen, USA) as both an interplate control and a positive control. The thermal profile of the RT-PCR procedure repeated for 50 cycles was: 1) $95 \mathrm{C}$ for 30s; 2) $5 \mathrm{~s}$ denaturation at 95C, $5 \mathrm{~s}$ annealing at $60 \mathrm{C}$ (amplification data collected at the end of each amplification step); 3) dissociation curve consisting of $10 \mathrm{~s}$ incubation at $95 \mathrm{C}, 5 \mathrm{~s}$ incubation at $65 \mathrm{C}$, a ramp up to $95 \mathrm{C}$ (Bio-rad CFX96 Real Time System, USA). Melting curves were used to validate product specificity. All samples were amplified in triplicates from the same total RNA preparation and the mean value was used for further analysis. Ct values of target genes greater than 37 were considered to be a negative call and assigned a value $=37$ for the purpose of normalization. Ct values of control wells (no-template control, positive control) were examined for each plate.

\section{ELISA}

Serum IL-18 levels were measured by Human IL-18 ELISA kit (R\&D systems, USA) according to manufacturers instructions. The limits of detection of the assay were at $12.5 \mathrm{pg} / \mathrm{mL}$. Active serum IL-1 $\beta$ levels were measured using Quantikine HS Human IL-1 $\beta$ immunoassay (R\&D systems, USA) according to manufacturer $\mathrm{s}$ instructions. The sensitivity ranges from $0.023 \mathrm{pg} / \mathrm{mL}$ to $0.14 \mathrm{pg} / \mathrm{mL}$. The limits of detection in this assay was at $0.125 \mathrm{pg} / \mathrm{mL}$.

\section{Data analysis}

Among samples that differed in their histologically determined severity scores, group comparisons (Table 1) were performed using non-parametric Mann Whitney $U$ test. Spearmans correlation analysis was carried out. In all cases, the $\mathrm{p}$ - values of $<0.05$ were considered to be significant.

\section{Results}

NALP4 and IL-1B encoding mRNAs are downregulated in visceral adipose of patients with pericellular fibrosis

Pericellular fibrosis scores were positively correlated with both the scores for portal fibrosis $(r=0.5321 ; p=0.0003)$ and the degree of hepatic steatosis $(r=0.3393 ; \mathrm{p}=0.03001)$.

Table 1 Demographic and clinical characteristics of patient cohorts profiled for expression of NALPs and other inflammasome components and targets

\begin{tabular}{ll}
\hline Demographic or clinical parameter $(\mathrm{N}=45)$ & $\begin{array}{l}\text { Average SD } \\
\text { or percentage }\end{array}$
\end{tabular}

Clinical \& Demographic Data

$\mathrm{BMI}$

47.410 .8

Age

42.711 .9

Gender (Females)

$62.2 \%$

Triglyceride $(\mathrm{mg} / \mathrm{dL})$

158.396 .7

AST (U/L)

27.718 .8

$\operatorname{ALT}(U / L)$

36.729 .3

Glucose $(\mathrm{mg} / \mathrm{dL})$

106.432 .2

Diabetes (Presence) $57.7 \%$

Liver Histological Data

Non-NASH NAFLD $\quad 55.5 \%$

NASH (Presence) $\quad 44.4 \%$

Ballooning Degeneration (Presence) 28.8\%

Mallory-Denk Bodies (Presence) $\quad 11.1 \%$

Portal Inflammation (Presence) $\quad$ 66.6\%

Advanced Lobular Inflammation (Score $\geq 3$ ) 28.8\%

Pericellular Fibrosis (Presence) $\quad 44.4 \%$

Portal Fibrosis (Presence) $\quad 75.5 \%$

Advanced Fibrosis (Score $\geq 3$ ) 31.1\%

Focal Necrosis (Presence) $\quad 31.1 \%$

Steatosis is histologically defined by the presence of $\geq 5 \%$ hepatic fat with/ without lobular inflammation and with/without portal inflammation. The degree of lobular inflammation is defined by the sum of the scores for the presence of lymphoplasmacytic cells, Kupffer cell hypertrophy and neutrophil infiltration. NASH is histologically defined by the presence of steatosis along with lobular inflammation, with/without ballooning degeneration and/or Mallory-Denk bodies and/or pericellular fibrosis. Lymphoplasmacytic cells, Kupffer cell hypertrophy and neutrophil infiltration was each scored on a scale of 03 : $0=$ none, $1=$ mild or few, $2=$ moderate, $3=$ marked or many. Portal inflammation, hepatocellular ballooning, pericellular/perisinusoidal fibrosis, and portal fibrosis were graded on a scale of 0 to 3: (0) none, (1) mild or few, (2) moderate, or (3) marked or many. Advanced fibrosis was defined by a sum of score of portal and pericellular fibrosis as being greater or equal to 3 . Bridging fibrosis was scored as (0) none, (1) few bridges, or (2) many bridges. Cirrhosis was scored as (0) absent, (1) incomplete, or (2) established [22]. 
In visceral adipose of patients with pericellular fibrosis, the levels of NALP4-encoding mRNA were significantly lower than that in the cohort without the pericellular fibrosis (0.18 0.20 vs $1.122 .53 ; \mathrm{p}<0.019)$ (Table 2). The levels of mRNA for an inflammatory cytokine IL-1B were also significantly lower in the group with pericellular fibrosis (6.17 12.05 vs $14.9618 .21 ; \mathrm{p}<0.003)$ (Table 2). Accordingly, adipose specific expression levels of NALP4 and IL1B mRNAs negatively correlated with pericellular fibrosis $(r=0.33 ; p<0.037$ and $r=0.47 ; p=0.002$, respectively), while circulating levels of IL-18 cytokine were positively correlated with the scores for this histopathological feature $(r=0.3365 ; \mathrm{p}<0.04)$.

\section{NALP6 encoding mRNA and serum levels of IL-18 are} upregulated in portal fibrosis

Expression levels of NALP6 mRNA were significantly higher in visceral adipose of patients with portal fibrosis as compared to that of the patients with no evidence of portal fibrosis $(0.860 .93$ vs $0.380 .38 ; \mathrm{p}=0.028)$

(Table 2). Interestingly, circulating levels of IL-18, an inflammatory cytokine that functions downstream of inflammasome, were significantly higher in patients with portal fibrosis $(390.95 \mathrm{pg} / \mathrm{mL} 176.84 \mathrm{pg} / \mathrm{mL}$ vs $246.08 \mathrm{pg} / \mathrm{mL}$ $103.10 \mathrm{pg} / \mathrm{mL} ; \mathrm{p}=0.022$ ) (Table 2). Accordingly, circulating levels of IL-18 were also positively correlated with the scores for portal fibrosis $(r=0.4226 ; \mathrm{p}<0.01)$.

\section{Adipose inflammasome signature associated with inflammatory features and NASH}

Among the genes assessed for expression, NALP 4, 5, 7, $8,9,10,11,13$ and IL-1B were significantly downregulated in adipose tissue samples collected from NASH cohort (Table 2).

CASP-1 mRNA expression levels in adipose were positively correlated with both the hepatic lobular inflammation

Table 2 Significantly altered targets in analyzed cohorts

\begin{tabular}{|c|c|c|c|}
\hline & Pericellular fibrosis presence $(\mathrm{N}=20)$ & Pericellular fibrosis absence $(\mathrm{N}=25)$ & $P$ value \\
\hline$\overline{\mathrm{AST}(\mathrm{U} / \mathrm{L})}$ & 34.7525 .06 & 22.629 .19 & 0.023 \\
\hline Males & $50.0 \%$ & $19.0 \%$ & 0.036 \\
\hline Females & $35.7 \%$ & $25 \%$ & NS \\
\hline Advanced fibrosis presence (Score $\geq 3$ ) & $60 \%$ & $9.5 \%$ & 0.0006 \\
\hline NALP4 mRNA & 0.180 .20 & 1.122 .53 & 0.019 \\
\hline \multirow[t]{2}{*}{ IL1B mRNA } & 6.1712 .05 & 14.9618 .21 & 0.003 \\
\hline & Portal fibrosis presence $(\mathrm{N}=34)$ & Portal fibrosis absence $(\mathrm{N}=11)$ & $P$ value \\
\hline Advanced fibrosis presence (Score $\geq 3$ ) & $45.2 \%$ & 0 & 0.008 \\
\hline $\mathrm{NASH}$ & $58.1 \%$ & $20 \%$ & 0.03 \\
\hline NALP6 mRNA & 0.860 .93 & 0.380 .38 & 0.028 \\
\hline \multirow[t]{2}{*}{ IL-18 (pg/mL) } & 390.95 pg/mL 176.84 & $246.08 \mathrm{pg} / \mathrm{mL} 103.10$ & 0.022 \\
\hline & NASH $(\mathrm{N}=20)$ & Non-NASH NAFLD $(\mathrm{N}=25)$ & $P$ value \\
\hline Gender (Females) & $50 \%$ & $81 \%$ & $<0.036$ \\
\hline Portal Fibrosis (presence) & 1.350 .67 & 0.710 .64 & $<0.005$ \\
\hline Pericellular Fibrosis (presence) & 1.450 .60 & 0.050 .22 & $<0.001$ \\
\hline Advanced fibrosis (Score $\geq 3$ ) & $60 \%$ & $9.5 \%$ & $<0.0006$ \\
\hline Degree of lobular inflammation & 2.551 .61 & 1.520 .98 & $<0.02$ \\
\hline AST $(U / L)$ & 35.7024 .79 & 21.718 .52 & $<0.004$ \\
\hline NALP 4 mRNA & 0.160 .19 & 1.142 .53 & $<0.002$ \\
\hline NALP 5 mRNA & 0.140 .12 & 1.242 .58 & $<0.02$ \\
\hline NALP 7 mRNA & 0.140 .12 & 1.092 .54 & $<0.03$ \\
\hline NALP 8 mRNA & 0.140 .12 & 1.092 .54 & $<0.03$ \\
\hline NALP 9 mRNA & 0.140 .12 & 1.252 .70 & $<0.03$ \\
\hline NALP 10 mRNA & 0.140 .12 & 1.092 .54 & $<0.03$ \\
\hline NALP 11 mRNA & 0.140 .12 & 1.092 .54 & $<0.02$ \\
\hline NALP 13 mRNA & 0.140 .12 & 1.092 .54 & $<0.03$ \\
\hline IL-1B mRNA & 8.7115 .45 & 12.6616 .68 & $<0.02$ \\
\hline
\end{tabular}


scores $(\mathrm{r}=0.3713 ; \mathrm{p}=0.016)$ and the histopathologically determined Kupffer cell hypertrophy $(r=0.41 ; p=0.006)$. Additionally, expression levels of NALP3 mRNA in adipose were positively correlated with serum levels of liver enzyme AST $(r=0.32 ; \mathrm{p}=0.03)$.

\section{Inflammasome components are co-regulated in adipose} The pattern of the correlation between expression levels for mRNAs encoding inflammasome components and its downstream targets (NALP1-14, ASC, CASP-1, IL-1B and IL-18 mRNA) shows that these genes are coregulated in adipose (Table 3). In our study, expression levels of NALP1 mRNA positively correlated with that of NALP4 $(\mathrm{r}=0.3984 ; \mathrm{p}=0.01)$, NALP11 $(\mathrm{r}=0.3294 ; \mathrm{p}=$ $0.04)$ and NALP14 $(\mathrm{r}=0.4134 ; \mathrm{p}=0.008)$. Expression levels of NALP2 mRNAs were positively correlated with that of all the other non-inflammasome forming NALP members (NALP4 - NALP14) as well as with levels of IL-18 mRNA $(\mathrm{r}=0.5241, \mathrm{p}<0.001)$. The expression levels of NALP3 mRNA were correlated with that of NALP5 $(\mathrm{r}=0.3188, \mathrm{p}=0.04)$, NALP12 $(\mathrm{r}=0.3662, \mathrm{p}=$ $0.02)$, NALP14 $(\mathrm{r}=0.3484, \mathrm{p}=0.027)$ as well as ASC $(\mathrm{r}=$ $0.78, \mathrm{p}<0.001)$ and CASP-1 $(\mathrm{r}=0.389, \mathrm{p}=0.012)$. The levels of NALP4 mRNA were co-correlated with levels of NALP5, NALP7-14 and IL-18 mRNA (Table 3), while levels of NALP5 mRNA were co-correlated with NALP714 and IL-18 mRNAs (Table 3). NALP6 mRNA levels were co-correlated with that of NALP12 $(\mathrm{r}=0.3227, \mathrm{p}=$ 0.048). The levels mRNAs for NALP7, NALP8, NALP9 and NALP10 were co-correlated with NALP11, NALP12, NALP14 and IL-18 mRNA (Table 3). The levels of NALP11 mRNA were co-correlated with NALP12/13/14 and IL-18 mRNA, the levels of NALP12 co-correlated with NALP13, NALP14, ASC and IL-18 mRNA, and the levels of NALP13 co-correlated with NALP14 and IL-18 mRNA. The levels of NALP14 were co-correlated with that of IL-18 mRNA, while the levels of ASC were cocorrelated with that of CASP-1 and IL-1B mRNAs.

\section{Discussion}

Systemic inflammation is a common finding in both visceral obesity and chronic liver disease $[25,26]$. Inflammasome activation has been recently recognized to play an increasingly important role in the development of liver disease [27-29]. However, the tissue source and mechanisms of inflammasome mediated liver damage in obesity associated NAFLD remain disputed [29,30]. Activation of inflammasomes involves two separate steps, the priming of tissue to inflammatory response that results in transcriptional activation of NALPs, IL18 and IL1B genes, and the activation of the inflammasome complex that culminates in the secretion of active pro-inflammatory IL- $1 \beta$ and IL-18 cytokines. To better understand the role of adipose specific inflammasome components in NAFLD, we assessed the adipose tissue mRNA for inflammasome components and serum levels of its downstream targets in 45 morbidly obese patients $(\mathrm{BMI} \geq 35)$ with various liver conditions of NAFLD spectrum.

Previous studies have shown that the NALP3 inflammasome and NALP3-dependent caspase-1 activation are central to the inflammation and the development of the liver fibrosis [31]. In our study, expression levels of NALP3 mRNA in adipose were positively correlated with serum levels of liver enzyme AST $(r=0.32 ; p=0.03)$ and the levels of mRNA encoding caspase- 1 were positively correlated with Kupffer cell hypertrophy and the hepatic lobular inflammation scores. However, to our surprise, the levels of mRNA encoding for NALP 4, 5, 7, 8, 9, 10, 11, 13 and IL-1B were significantly downregulated in adipose tissue samples collected from NASH cohort as compared to patients without NASH (Table 2). Moreover, the expression patterns of mRNA for many NALPs, especially for non-inflammasome forming NALPs, were co-correlated to each other (Table 3).

So far, only NALPs 13 have been shown to form active inflammasome, while the functions of other NALPs remain obscure [9]. Some NALP proteins, for example, NALP12 and NALP6, have been previously shown to suppress inflammation through downregulation of NF-kB signaling subsequent to TLR activation [3]. Another revolving theme in the study of non-classic NALPs, for example, NALP5, NALP7, NALP8 and NALP9 is their involvement in oocyte maturation, implantation and other fertility-related processes [32,33]. It is tempting to speculate that the decrease in adipocytic expression of these NALPs may contribute to decreased fertility in patients with NASH and metabolic syndrome, possibly through known association of NASH with polycystic ovary syndrome (PCOS) [34,35]. Non-inflammasome related NALPs may also play as yet unknown roles in pathogenesis of obesity-associated disorders through modulation of adipocytic secretion or other pathways.

Interestingly, mRNAs encoding for NALP4 and its substrate IL1B were both downregulated in the cohort with hepatic pericellular fibrosis, while recently published study of Boaru et al. showed time and concentrationdependent increase in expression of NALP4 in cultured hepatic stellate cells upon lipopolysacharride (LPS) stimulation [29]. This would suggest a role for NALP4 in promoting fibrotic response by activated stellate cells. The contradiction between our data and observation of Boaru et al. [29] may be attributed to either yet unknown tissue specific differences in the function of NALP4, or to a negative feedback signal operating between adipose tissue and liver which may be, in fact, time dependent. It is possible that the inflammation and the fibrotic processes may be initiated in adipose tissue as described Reggio et al., [36], but later be shifted to distant organs such as liver. This 
Table 3 Correlation among mRNA expression levels of inflammasome components

\begin{tabular}{|c|c|c|c|c|c|c|c|c|c|c|c|c|c|c|c|c|c|c|}
\hline $\begin{array}{l}\text { Rho } \\
\text { (p-value) }\end{array}$ & NALP1 & NALP2 & NALP3 & NALP4 & NALP5 & NALP6 & NALP7 & NALP8 & NALP9 & NALP10 & NALP11 & NALP12 & NALP13 & NALP14 & IL18 & ASC & CASP1 & IL1B \\
\hline NALP1 & - & - & - & $\begin{array}{l}0.3984 \\
(0.01)\end{array}$ & - & - & - & - & - & - & $\begin{array}{l}0.3294 \\
(0.04)\end{array}$ & - & - & $\begin{array}{l}0.4134 \\
(0.008)\end{array}$ & - & - & - & - \\
\hline NALP2 & - & - & - & $\begin{array}{l}0.5336 \\
(<0.001)\end{array}$ & $\begin{array}{l}0.5068 \\
(<0.001)\end{array}$ & $\begin{array}{l}0.394 \\
(0.01)\end{array}$ & $\begin{array}{l}0.5274 \\
(<0.001)\end{array}$ & $\begin{array}{l}0.5274 \\
(<0.001)\end{array}$ & $\begin{array}{l}0.5274 \\
(<0.001)\end{array}$ & $\begin{array}{l}0.5274 \\
(<0.001)\end{array}$ & $\begin{array}{l}0.5096 \\
(<0.001)\end{array}$ & $\begin{array}{l}0.5231 \\
(<0.001)\end{array}$ & $\begin{array}{l}0.5274 \\
(<0.001)\end{array}$ & $\begin{array}{l}0.4799 \\
(0.001)\end{array}$ & - & - & - & - \\
\hline NALP3 & - & - & - & - & $\begin{array}{l}0.3188 \\
(0.044)\end{array}$ & - & - & - & - & - & - & $\begin{array}{l}0.3662 \\
(0.02)\end{array}$ & - & $\begin{array}{l}0.3484 \\
(0.027)\end{array}$ & - & $\begin{array}{l}0.7826 \\
(<0.001)\end{array}$ & $\begin{array}{l}0.389 \\
(0.012)\end{array}$ & - \\
\hline NALP4 & - & - & - & - & $\begin{array}{l}0.8199 \\
(<0.0001)\end{array}$ & - & $\begin{array}{l}0.8375 \\
(<0.0001)\end{array}$ & $\begin{array}{l}0.8375 \\
(<0.0001)\end{array}$ & $\begin{array}{l}0.8375 \\
(<0.0001)\end{array}$ & $\begin{array}{l}0.8375 \\
(<0.0001)\end{array}$ & $\begin{array}{l}0.8786 \\
(<0.0001)\end{array}$ & $\begin{array}{l}0.6051 \\
(<0.0001)\end{array}$ & $\begin{array}{l}0.8375 \\
(<0.0001)\end{array}$ & $\begin{array}{l}0.8317 \\
(<0.0001)\end{array}$ & $\begin{array}{l}0.3937 \\
(0.01)\end{array}$ & - & - & - \\
\hline NALP5 & - & - & - & - & - & - & $\begin{array}{l}0.9856 \\
(<0.0001)\end{array}$ & $\begin{array}{l}0.9856 \\
(<0.0001)\end{array}$ & $\begin{array}{l}0.9856 \\
(<0.0001)\end{array}$ & $\begin{array}{l}0.9856 \\
(<0.0001)\end{array}$ & $\begin{array}{l}0.9786 \\
(<0.0001)\end{array}$ & $\begin{array}{l}0.7439 \\
(<0.0001)\end{array}$ & $\begin{array}{l}0.9856 \\
(<0.0001)\end{array}$ & $\begin{array}{l}0.8829 \\
(<0.0001)\end{array}$ & $\begin{array}{l}0.564 \\
(<0.0001)\end{array}$ & - & - & - \\
\hline NALP6 & - & - & - & - & - & - & - & - & - & - & - & 0.3227 & - & - & - & - & - & - \\
\hline NALP7 & - & - & - & - & - & - & - & - & - & - & $\begin{array}{l}0.9931 \\
(<0.0001)\end{array}$ & $\begin{array}{l}0.7672 \\
(<0.0001)\end{array}$ & - & $\begin{array}{l}0.9023 \\
(<0.0001)\end{array}$ & $\begin{array}{l}0.5581 \\
(<0.0001)\end{array}$ & - & - & - \\
\hline NALP8 & - & - & - & - & - & - & - & - & - & - & $\begin{array}{l}0.9931 \\
(<0.0001)\end{array}$ & $\begin{array}{l}0.7672 \\
(<0.0001)\end{array}$ & - & $\begin{array}{l}0.9023 \\
(<0.0001)\end{array}$ & $\begin{array}{l}0.5581 \\
(<0.001)\end{array}$ & - & - & - \\
\hline NALP9 & - & - & - & - & - & - & - & - & - & - & $\begin{array}{l}0.9931 \\
(<0.0001)\end{array}$ & $\begin{array}{l}0.7672 \\
(<0.0001)\end{array}$ & - & $\begin{array}{l}0.9023 \\
(<0.0001)\end{array}$ & $\begin{array}{l}0.5581 \\
(<0.001)\end{array}$ & - & - & - \\
\hline NALP10 & - & - & - & - & - & - & - & - & - & - & $\begin{array}{l}0.9931 \\
(<0.0001)\end{array}$ & $\begin{array}{l}0.7672 \\
(<0.0001)\end{array}$ & - & $\begin{array}{l}0.9023 \\
(<0.0001)\end{array}$ & $\begin{array}{l}0.5581 \\
(<0.001)\end{array}$ & - & - & - \\
\hline NALP11 & - & - & - & - & - & - & - & - & - & - & - & $\begin{array}{l}0.758 \\
<0.0001)\end{array}$ & $\begin{array}{l}0.9931 \\
(<0.0001)\end{array}$ & $\begin{array}{l}0.9212 \\
(<0.0001)\end{array}$ & $\begin{array}{l}0.5478 \\
(<0.001)\end{array}$ & - & - & - \\
\hline NALP12 & - & - & - & - & - & - & & - & - & - & - & - & $\begin{array}{l}0.7672 \\
(<0.0001)\end{array}$ & $\begin{array}{l}0.8437 \\
(<0.0001)\end{array}$ & $\begin{array}{l}0.514 \\
(<0.001)\end{array}$ & $\begin{array}{l}0.3657 \\
(0.02)\end{array}$ & - & - \\
\hline NALP13 & - & - & - & - & - & - & - & - & - & - & - & - & - & $\begin{array}{l}0.9023 \\
(<0.0001)\end{array}$ & $\begin{array}{l}0.5581 \\
(<0.001)\end{array}$ & - & - & - \\
\hline NALP14 & - & - & - & - & - & - & - & - & - & - & - & - & - & - & $\begin{array}{l}0.5751 \\
(0.0001)\end{array}$ & - & - & - \\
\hline IL18 & - & - & - & - & - & - & - & - & - & - & - & - & - & - & - & - & - & - \\
\hline ASC & - & - & - & - & - & - & - & - & - & - & - & - & - & - & - & - & - & $\begin{array}{l}0.3931 \\
(0.01)\end{array}$ \\
\hline CASP & - & - & - & - & - & - & - & - & - & - & - & - & - & - & - & - & - & - \\
\hline IL1B & - & - & - & - & - & - & - & - & - & - & - & - & - & - & - & - & - & - \\
\hline
\end{tabular}


may be accompanied with negative feedback signaling that originates in the liver and attempts to restore homeostasis.

The observed downregulation of adipose-specific production of IL1B mRNA in patients with pericellular fibrosis (Table 2 and Figure 1) as well as NASH (Table 2 and Figure 2) also supports this hypothesis. The downregulation at expression level is also supported by the lack of detectable IL1B protein levels in circulation (Assay Range: $0.125-8 \mathrm{pg} / \mathrm{mL}$ ). Unlike the production of most inflammatory cytokines, the production of biologically active IL-1 $\beta$ is dependent on transcription, translation, maturation and secretion mechanisms, all of which are tightly regulated in tissue-specific manner. This may be attributed to tissue specific roles of IL1B. Animal studies showed that hepatic IL-1 $\beta$ protein and mRNA levels to be increased in various diet-induced NASH models in mice [28], while adipose specific IL1B deficiency in mice increase susceptibility to obesity $[28,37]$. In another recent study, the authors demonstrate in animal models that IL-1 $\beta$ supports ectopic fat accumulation in hepatocytes and adipose-tissue macrophages, contributing to impaired fat-liver crosstalk in nutritional obesity [38]. While the translation of animal studies to humans is difficult, the discrepancy in observed expression levels of IL1B in obesity associated $\mathrm{NASH}$ and pericellular fibrosis maybe attributed to the extremely high BMI of the cohort being examined $(B M I \geq 35)$. This along with the observed negative correlation of IL1B mRNA levels with BMI $(r=0.317$; $\mathrm{p}=0.04)$ indicates an ongoing negative feedback loop between adipose specific IL1B expression and an accumulation of VAT.

Further support to the hypothesis centering on ongoing negative feedback loop operating between adipose tissue and liver in morbidly obese individuals with severe NAFLD, is provided by result of the comparison in another cohort. In cohort of subjects with portal fibrosis compared to those without portal fibrosis, adipose specific NALP6 mRNA (Table 2 and Figure 3) and circulating IL18 (Table 2 and Figure 3) protein were upregulated with hepatic portal fibrosis, while adipose specific IL18 mRNA was not significantly different in the same cohort. This is interesting, since NALP6 has been shown to have an antiinflammatory role by downregulating NF- $\mathrm{kB}$ signaling subsequent to TLR activation [3]. Conspicuously, whilst circulating IL-18 protein was upregulated in portal fibrosis (Table 2 and Figure 3), this was not accompanied with an upregulation of adipose specific IL18 mRNA. Additionally, circulating IL-18 was found to be positively correlated with BMI $(r=0.41 ; p=0.012)$. This is in agreement with previous studies [39-43]. Notably, circulating IL-18 levels are also associated with increased liver injury markers [44]: $\operatorname{AST}(r=0.33 ; p=0.04)$ and ALT $(r=0.41 ; p=0.01)$ levels respectively as seen in previous reports [43]. Since IL-18 is more widely expressed, this may indicate additional sources of circulating IL-18 protein such as from the gut [28] or the liver [45], playing a role in the inflammation and hepatic injury progression. Thus, IL-18 might contribute to the development of liver disease, albeit the origin of IL-18 may not be solely from adipose.

For the first time, we profiled gene expression profile of all the 14 members of NALPs in visceral adipose tissue. As can be seen from correlation analysis (Table 3), the expression of these genes is significantly correlated with each other. While most of the studies on obesity and insulin resistance have focused on NALP3 mediated inflammasome, our study showed that there is a need for exploring roles of other members of this family of proteins in systemic inflammation and chronic liver conditions.

Among the limitations of this study is that the gene expression analysis has been carried out in whole

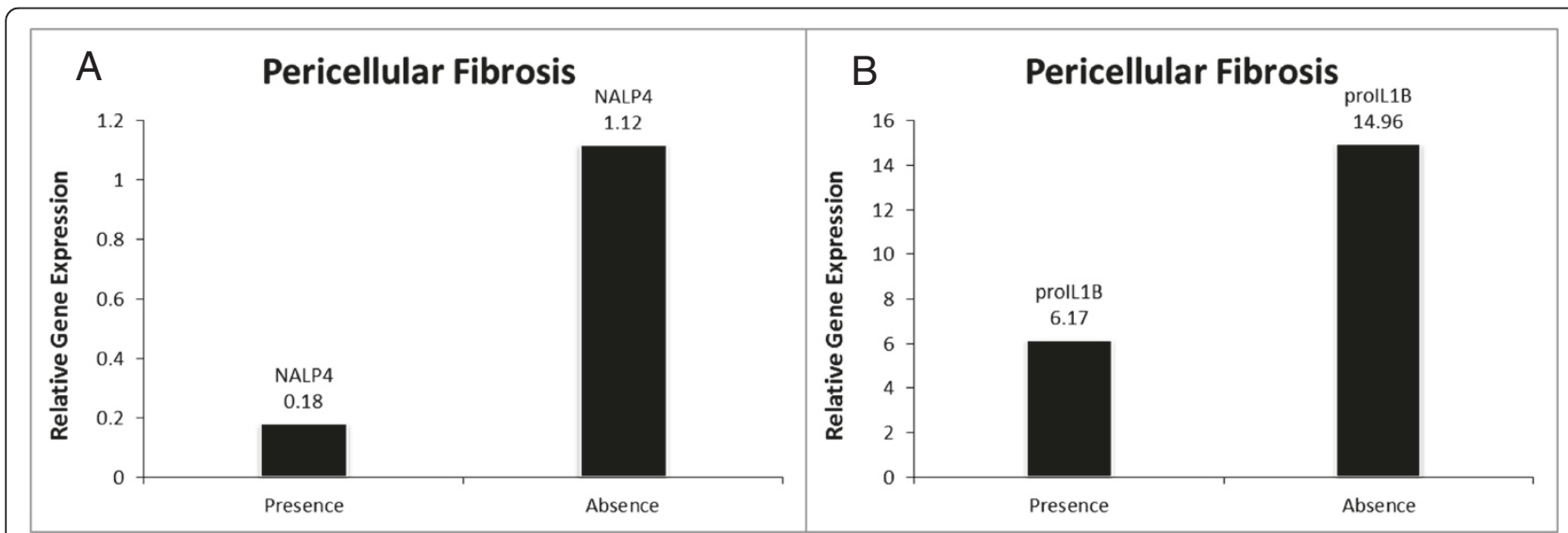

Figure 1 Significantly altered gene expression in presence of pericellular fibrosis vs absence of pericellular fibrosis. A.) NALP4 gene expression; B.) IL1B gene expression. 


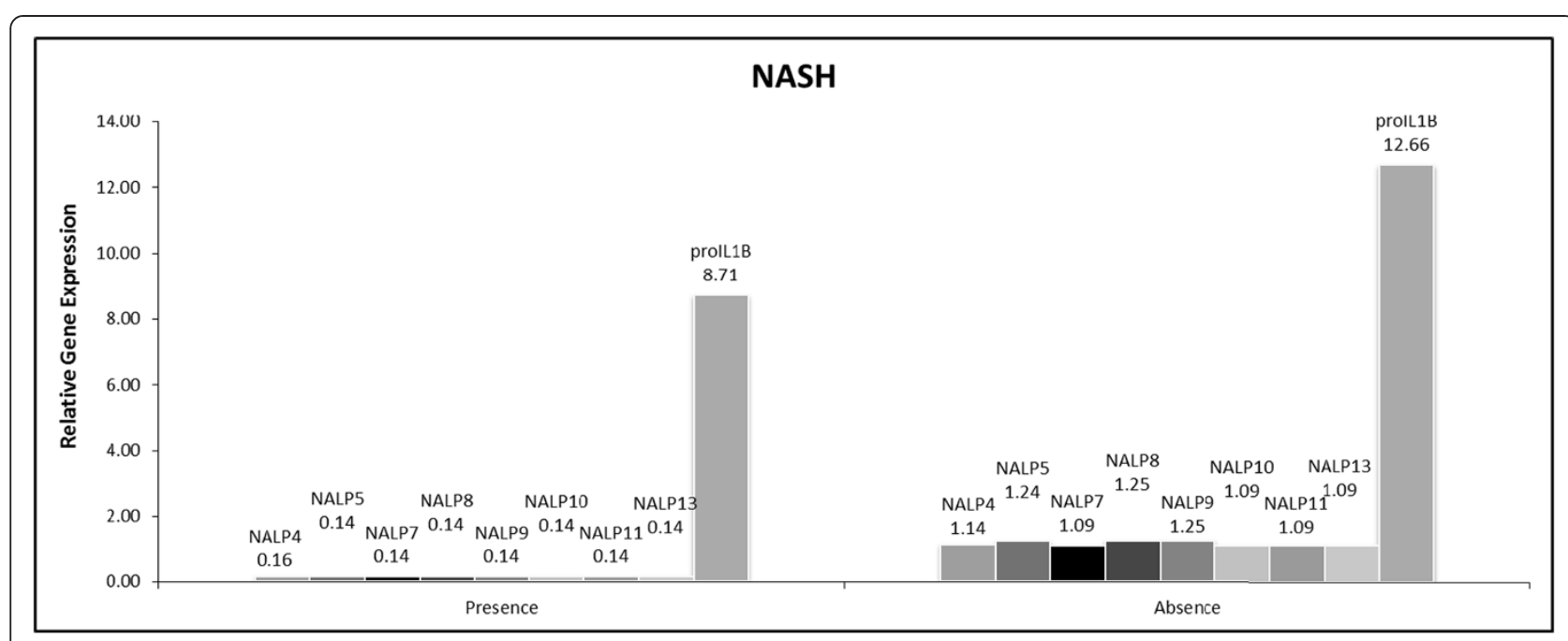

Figure 2 Significantly altered gene expression in presence of NASH vs non-NASH NAFLD.

adipose tissue instead of studying isolated tissue components, i.e. adipocytes and stromal vascular cells. This study was limited to two markers of systemic inflammation, IL1B and IL18 that were selected as known targets released into circulation upon activation. The profiling of greater variety of inflammatory molecules may yield better mechanistic resolution of inflammatory responses in adipose. Another avenue to explore is the parallel study of NALP component expression in liver and other peripheral tissues, and the study of NALP components at protein level.

\section{Conclusion}

The results of our study indicate that non-inflammasome related NALPs may play as yet unknown roles in pathogenesis of obesity-associated disorders through modulation of adipocytic secretion or other pathways. Our observations also point at a possible shift in inflammation and fibrotic response from adipose tissue to liver in patients with severe obesity. While this hypothesis needs further experimental verification, it takes us a step closer in understanding the underlying reason for some obese individuals being metabolically healthy as compared to

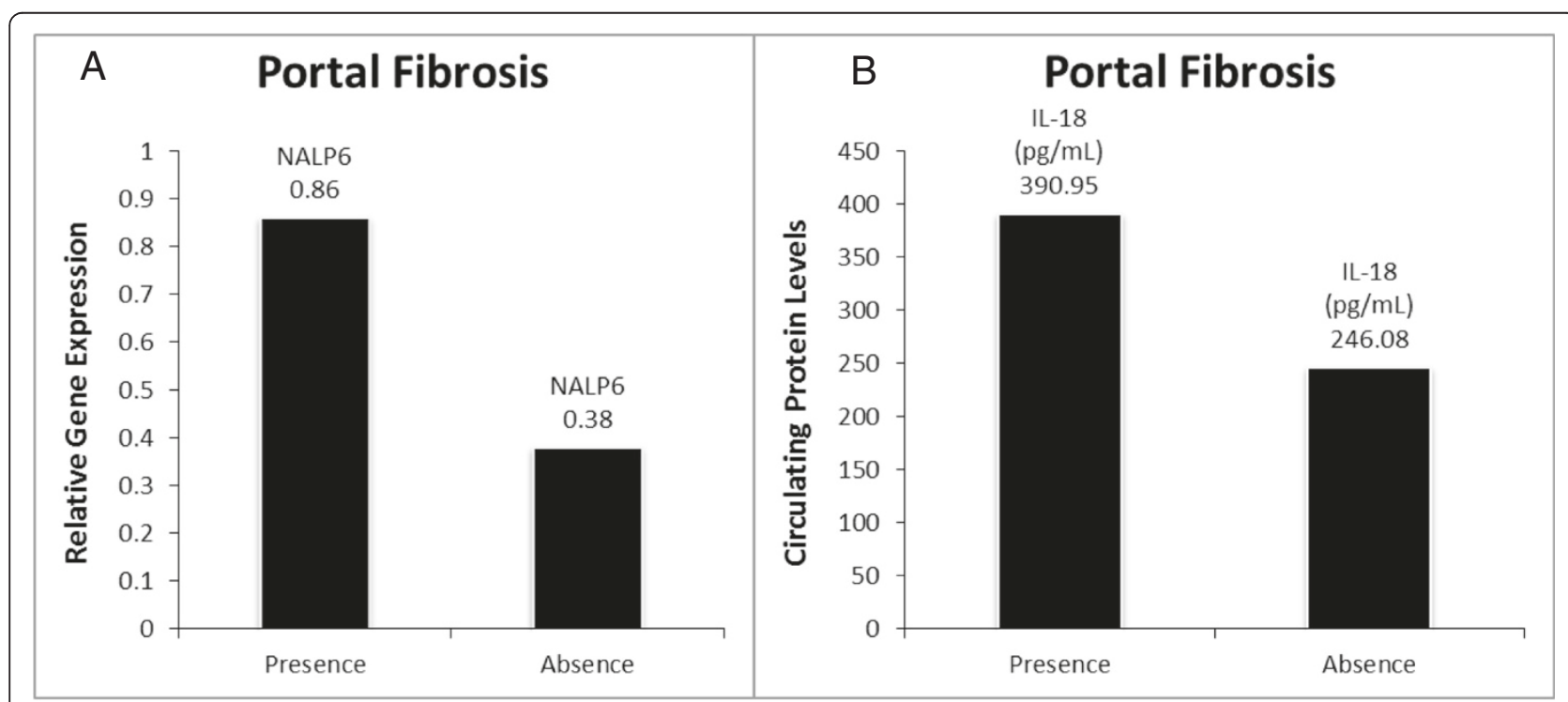

Figure 3 Significantly altered targets in presence of portal fibrosis vs absence of portal fibrosis. A.) NALP6 gene expression; B.) Circulating IL18 levels. 
metabolically unhealthy obese. Additional study of matched liver and adipose tissues from same individuals will help delineate the cross talk mechanisms between inflammation and fibrosis in obesity and NAFLD.

\section{Additional file}

Additional file 1: Table S1. A list of validated primers.

\begin{abstract}
Abbreviations
NAFLD: Non-alcoholic fatty liver disease; NALPs: NACHT, LRR and PYD domains-containing proteins; NASH: Non-alcoholic steatohepatitis; ASC: Apoptosis-associated speck-like protein containing a CARD; IL-18: Interleukin-18; IL-1ß: Interleukin- 1Beta; BMI: Body mass index; AST: Aspartate aminotransferase; ALT: Alanine aminotransferase; DAMPs: Damage-associated molecular patterns; PRRs: Pattern-recognition receptors; NLRs: Nucleotide oligomerization and binding domain NOD-like receptors; IL-33: Interleukin-33; IL-6: Interleukin-6; TNF-a: Tumor necrosis factor-alpha; IFN-ү: Interferon-gamma; IL-17: Interleukin-17; PCOS: Polycystic ovary syndrome.
\end{abstract}

\section{Competing interests}

The authors declare that they have no competing interests.

\section{Authors contributions}

RM conceived and designed the study, carried out the ELISA and GRT-PCR studies, provided daily supervision for AN, a MS student and drafted the manuscript. AN validated the primers and assisted in GRT-PCR studies. LW carried out statistical analysis of data. ZG provided the histopathological assessment of liver biopsies. AB participated in its design and finalized the manuscript. ZM participated in the design of the study. All authors read and approved the final manuscript.

\section{Acknowledgements}

This work has been performed at the Translational Research Institute, as part of the collaborative effort between George Mason University and Inova Fairfax Hospital. We would like to thank both our Inova and George Mason teams for their invaluable help and assistance. This study was funded by an Internal Seed grant from Inova Health System.

\section{Author details}

${ }^{1}$ Betty and Guy Beatty Obesity and Liver Program, Inova Health System, Falls Church, VA, USA. ${ }^{2}$ Center for the Study of Chronic Metabolic Diseases, School of Systems Biology, College of Science, George Mason University, Fairfax, VA, USA. ${ }^{3}$ Center for Liver Diseases and Department of Medicine, Inova Fairfax Hospital, Falls Church, VA, USA.

Received: 13 August 2014 Accepted: 27 November 2014

Published online: 16 December 2014

\section{References}

1. Flegal KM, Caroll MD: PRevalence of obesity and trends in the distribution of body mass index among us adults, 1999 2010. JAMA 2012, 307:491 497.

2. Kubes $P$, Mehal WZ: Sterile inflammation in the liver. Gastroenterology 2012, 143:1158 1172.

3. Kono H, Rock KL: How dying cells alert the immune system to danger. Nat Rev Immunol 2008, 8:279 289.

4. Rock KL, Latz E, Ontiveros F, Kono $\mathrm{H}$ : The sterile inflammatory response. Annu Rev Immunol 2010, 28:321 342.

5. Maslanik T, Mahaffey L, Tannura K, Beninson L, Greenwood BN, Fleshner M: The inflammasome and danger associated molecular patterns (DAMPs) are implicated in cytokine and chemokine responses following stressor exposure. Brain Behav Immun 2013, 28:54 62.

6. Wilmanski JM, Petnicki-Ocwieja T, Kobayashi KS: NLR proteins: integral members of innate immunity and mediators of inflammatory diseases. J Leukoc Biol 2008, 83:13 30.
7. Lupfer C, Kanneganti T-D: The expanding role of NLRs in antiviral immunity. Immunol Rev 2013, 255:13 24.

8. Martinon F, Gaide O, Ptrilli V, Mayor A, Tschopp J: NALP Inflammasomes: a central role in innate immunity. Semin Immunopathol 2007, 29:213 229.

9. Tschopp J, Martinon F, Burns K: NALPs: a novel protein family involved in inflammation. Nat Rev Mol Cell Biol 2003, 4:95 104.

10. Bryan NB, Dorfleutner A, Rojanasakul Y, Stehlik C: Activation of inflammasomes requires intracellular redistribution of the apoptotic speck-like protein containing a caspase recruitment domain. J Immunol 2009, 182:3173 3182.

11. Dinarello CA: Interleukin-1, interleukin-1 receptors and interleukin-1 receptor antagonist. Int Rev Immunol 1998, 16:457 499.

12. Martinon F, Burns K, Tschopp J: The inflammasome: a molecular platform triggering activation of inflammatory caspases and processing of prolL-beta. Mol Cell 2002, 10:417 426

13. Martinon F, Tschopp J: Inflammatory caspases and inflammasomes: master switches of inflammation. Cell Death Differ 2006, 14:10 22.

14. Sims JE, Smith DE: The IL-1 family: regulators of immunity. Nat Rev Immunol 2010, 117:89 102

15. Ben-Sasson SZ, Hogg A, Hu-Li J, Wingfield P, Chen X, Crank M, CaucheteuX S, Ratner-Hurevich M, Berzofsky JA, Nir-Paz R, Paul WE: IL-1 enhances expansion, effector function, tissue localization, and memory response of antigen-specific CD8 T cells. J Exp Med 2013, 210:491 502.

16. Dinarello CA: The interleukin-1 family: 10 years of discovery. FASEB J 1994, 8:1314 1325.

17. Nakanishi K, Yoshimoto T, Tsutsui H, Okamura H: Interleukin-18 is a unique cytokine that stimulates both Th1 and Th2 responses depending on its cytokine milieu. Cytokine Growth Factor Rev 2001, 12:53 72.

18. Baranova A, Collantes R, Gowder SJ, Elariny H, Schlauch K, Younoszai A, King S, Randhawa M, Pusulury S, Alsheddi T, Ong JP, Martin LM, Chandhoke V, Younossi ZM: Obesity-related differential gene expression in the visceral adipose tissue. Obes Surg 2005, 15:758 765

19. Lago F, Dieguez C, Gmez-Reino J, Gualillo O: Adipokines as emerging mediators of immune response and inflammation. Nat Clin Pract Rheumatol 2007, 3:716 724

20. Powell K: Obesity: the two faces of fat. Nature 2007, 447:525 527

21. Gerner RR, Wieser $V$, Moschen AR, Tilg H: Metabolic inflammation: role of cytokines in the crosstalk between adipose tissue and liver1. Can J Physiol Pharmacol 2013, 91:867 872.

22. Younossi ZM, Stepanova M, Rafiq N, Makhlouf H, Younoszai Z, Agrawal R Goodman Z: Pathologic criteria for nonalcoholic steatohepatitis: interprotocol agreement and ability to predict liver-related mortality. Hepatology 2011, 53:1874 1882

23. Ye J, Coulouris G, Zaretskaya I, Cutcutache I, Rozen S, Madden TL: PrimerBLAST: a tool to design target-specific primers for polymerase chain reaction. BMC Bioinformatics 2012, 13:134.

24. Mehta R, Birerdinc A, Hossain N, Afendy A, Chandhoke V, Younossi Z Baranova A: Validation of endogenous reference genes for qRT-PCR analysis of human visceral adipose samples. BMC Mol Biol 2010, 11:39.

25. Berg $A H$, Scherer PE: Adipose tissue, inflammation, and cardiovascular disease. Circ Res 2005, 96:939 949.

26. Fontana L, Eagon JC, Trujillo ME, Scherer PE, Klein S: Visceral fat adipokine secretion is associated with systemic inflammation in obese humans. Diabetes 2007, 56:1010 1013.

27. Benetti E, Chiazza F, Patel NSA, Collino M: The NLRP3 inflammasome as a novel player of the intercellular crosstalk in metabolic disorders. Mediat Inflamm 2013, 2013:678627.

28. Szabo G, Csak T: Inflammasomes in liver diseases. J Hepatol 2012, 57:642 654.

29. Boaru SG, Borkham-Kamphorst E, Tihaa L, Haas U, Weiskirchen R: Expression analysis of inflammasomes in experimental models of inflammatory and fibrotic liver disease. J Inflamm 2012, 9:49.

30. Henao-Mejia J, Elinav E, Jin C, Hao L, Mehal WZ, Strowig T, Thaiss CA, Kau AL, Eisenbarth SC, Jurczak MJ, Camporez J-P, Shulman Gl, Gordon Jl, Hoffman HM, Flavell RA: Inflammasome-mediated dysbiosis regulates progression of NAFLD and obesity. Nature 2012, 482:179 185.

31. Wree A, Eguchi A, McGeough MD, Pena CA, Johnson CD, Canbay A, Hoffman HM, Feldstein AE: NLRP3 inflammasome activation results in hepatocyte pyroptosis, liver inflammation and fibrosis. Hepatology 2014, 59(3):898 910.

32. Ponsuksili S, Brunner RM, Goldammer T, Khn C, Walz C, Chomdej S, Tesfaye D, Schellander K, Wimmers K, Schwerin M: Bovine NALP5, NALP8, and 
NALP9 genes: assignment to a QTL region and the expression in adult tissues, oocytes, and preimplantation embryos. Biol Reprod 2006, 74:577 584

33. Zhang P, Dixon M, Zucchelli M, Hambiliki F, Levkov L, Hovatta O, Kere J: Expression analysis of the NLRP gene family suggests a role in human preimplantation development. PLOS ONE 2008, 3(7):e2755.

34. Baranova A, Tran TP, Afendy A, Wang L, Shamsaddini A, Mehta R, Chandhoke V, Birerdinc A, Younossi ZM: Molecular signature of adipose tissue in patients with both non-alcoholic fatty liver disease (NAFLD) and polycystic ovarian syndrome (PCOS). J Transl Med 2013, 11:133.

35. Baranova A, Tran TP, Birerdinc A, Younossi ZM: Systematic review: association of polycystic ovary syndrome with metabolic syndrome and non-alcoholic fatty liver disease. Aliment Pharmacol Ther 2011, 33:801 814.

36. Reggio S, Pellegrinelli V, Clment K, Tordjman J: Fibrosis as a cause or a consequence of white adipose tissue inflammation in obesity. Curr Obes Rep 2013, 2:1 9.

37. Garca MC, Wernstedt I, Berndtsson A, Enge M, Bell M, Hultgren O, Horn M, Ahrn B, Enerback S, Ohlsson C, Wallenius V, Jansson J-O: Mature-onset obesity in interleukin-1 receptor I knockout mice. Diabetes 2006, 55:1205 1213.

38. Kotas ME, Jurczak MJ, Annicelli C, Gillum MP, Cline GW, Shulman Gl, Medzhitov R: Role of caspase-1 in regulation of triglyceride metabolism. PNAS 2013, 110:4810 4815 .

39. Nov O, Shapiro H, Ovadia H, Tarnovscki T, Dvir I, Shemesh E, Kovsan J, Shelef I, Carmi Y, Voronov E, Apte RN, Lewis E, Haim Y, Konrad D, Bashan N, Rudich A: Interleukin- $1 \beta$ regulates fat-liver crosstalk in obesity by auto-paracrine modulation of adipose tissue inflammation and expandability. PLOS ONE 2013, 8:e53626.

40. Bruun JM, Stallknecht B, Helge JW, Richelsen B: Interleukin-18 in plasma and adipose tissue: effects of obesity, insulin resistance, and weight loss. Eur J Endocrinol 2007, 157:465 471.

41. Esposito K, Pontillo A, Ciotola M, Di Palo C, Grella E, Nicoletti G, Giugliano D: Weight loss reduces interleukin-18 levels in obese women. $J$ Clin Endocrinol Metab 2002, 87:3864 3866.

42. Membrez M, Ammon-Zufferey C, Philippe D, Aprikian O, Monnard I, Mac K, Darimont $C:$ Interleukin-18 protein level is upregulated in adipose tissue of obese mice. Obesity 2009, 17:393 395.

43. Wang H-N, Wang Y-R, Liu G-Q, Liu Z, Wu P-X, Wei X-L, Hong T-P: Inhibition of hepatic interleukin-18 production by rosiglitazone in a rat model of nonalcoholic fatty liver disease. World J Gastroenterol 2008, 14:7240 7246.

44. Paschos $P$, Paletas $K$ : Non alcoholic fatty liver disease and metabolic syndrome. Hippokratia 2009, 13:9 19.

45. Finotto S, Siebler J, Hausding M, Schipp M, Wirtz S, Klein S, Protschka M, Doganci A, Lehr HA, Trautwein C, Khosravi-Far R, Strand D, Lohse A, Galle PR, Blessing M, Neurath MF, Khosravi-Fahr R: Severe hepatic injury in interleukin 18 (IL-18) transgenic mice: a key role for IL-18 in regulating hepatocyte apoptosis in vivo. Gut 2004, 53:392 400.

\section{Submit your next manuscript to BioMed Central and take full advantage of:}

$\otimes$ Convenient online submission

$\otimes$ Thorough peer review

$\otimes$ No space constraints or color $₫$ gure charges

$\triangle$ Immediate publication on acceptance

\Inclusion in PubMed, CAS, Scopus and Google Scholar

$\nabla$ Research which is freely available for redistribution

Submit your manuscript at www.biomedcentral.com/submit 